\title{
Osmotic Dehydration of Pumpkin Using Response Surface Methodology - Influences of Operating Conditions on Water Loss and Solute Gain
}

\section{S.M. Atiqure Rahman'1, M. Enamul Hoque ${ }^{2 *}$, S. Rahman ${ }^{3}$ and M. Hasanuzzaman ${ }^{4}$}

${ }^{1}$ Sustainable and Renewable Energy Engineering, University of Sharjah, University City, 27272 Sharjah, United Arab Emirates ${ }^{2}$ Department of Mechanical, Materials and Manufacturing Engineering, University of Nottingham Malaysia Campus, 43500 Selangor Darul Ehsan, Malaysia ${ }^{3}$ Centre of Research Excellence in Renewable Energy (CoRE-RE), King Fahd University of Petroleum and Minerals (KFUPM), Dhahran 31261, Kingdom of Saudi Arabia ${ }^{4}$ Higher Institution Centre of Excellence, University of Malaya, 50603 Kuala Lumpur, Malaysia

\begin{abstract}
Response surface methodology (RSM) is a powerful tool in the area of process and product improvements. It is a collection of experimental designs and optimization techniques that enables the investigator to determine the relationship between independent variables and the obtained responses. This study focuses on the osmotic dehydration of pumpkin slices using response surface methodology investigating the influences of operating conditions on water loss and solute gain The operating conditions were varied by changing the independent process variables in a range e.g. salt concentrations from $5 \%$ to $25 \%(\mathrm{w} / \mathrm{v})$, salt solution temperatures from $30^{\circ} \mathrm{C}$ to $70^{\circ} \mathrm{C}$ and processing time from 30 to 150 minutes. Results showed that all the process variables had significant influences on both water loss and solute gain. However, the solution concentration was observed to be the most influential parameter followed by processing time and solution temperature. The optimum operating conditions that caused maximum water loss and minimum solute gain were found to be at solution temperature of $65.8^{\circ} \mathrm{C}$, salt concentration of $25 \%$ and processing time of 63 minutes In conclusion, this study provides a strong guideline for efficient drying of seasonal crop (e.g. pumpkin) in industrial application without compromising quality.
\end{abstract}

Keywords: Osmotic dehydration; Pumpkin; Response surface methodology; Operating conditions; Water loss; Solute gain

Nomenclature: Y: Dependent variable; X: Coded independent variable; $\mathrm{W}$ : Initial weight of pumpkin, $\%(\mathrm{w} / \mathrm{w})$; $\mathrm{W}$ : Weight of pumpkin after osmotic dehydration, $\%(w / w) ; S$ Bone dry mass of pumpkin, gm; $S_{t}$ : Bone dry mass of pumpkin after osmotic dehydration, gm; $\beta$ : Constant coefficient

\section{Introduction}

Pumpkin is a seasonal crop that is directly consumed as human food and/or used as ingredient, similar to palm fruit [1] to prepare processed foods. It covers a wide number of species of the family Cucurbitaceae. It is rich in vitamin $A$ and antioxidant carotenoids, particularly alpha and beta-carotenes. It is also a rich source of vitamins $\mathrm{C}, \mathrm{K}, \mathrm{E}$ and several other minerals such as magnesium, potassium and iron [2,3]. Pumpkin has very high potential for osmotic dehydration [4-7].

Osmotic dehydration is a method of dewatering by placing solid food (whole or in pieces) in sugars or salt aqueous solution of high osmotic pressure. The difference in the chemical potential of osmotic agent and the water in food give rise to two major simultaneous countercurrent flows: one is the water diffusing from food into the solution and the other is the solute diffusing from the surrounding solution into the food [8]. Freezing, freeze-drying, microwave drying and airdrying processes are carried out using Osmotic dehydration. These processes improve nutritional, sensorial and functional properties of fruits without changing their integrity [9]. The efficiency of osmotic dehydration is governed by the several factors such as concentration and type of osmotic solution, temperature, time, size, shape and ratio of material-to-osmotic solution [10]. Numerous studies showed that the operating parameters influenced the osmotic dehydration of vegetables [11-13]. The effective diffusivity of sucrose was reported to be decreased with the increase of the concentration of the sucrose solution, while the effective diffusivity of water increased [14]. The rates of water loss and solid gain were also influenced by the concentration, temperature and sample geometry [15]. However, it still remains rather challenging to establish general rule about the parameters that affect osmotic dehydration. Response surface methodology (RSM) is a collection of statistical and mathematical techniques and is considered to be very useful for developing, improving and optimizing processes. The major applications of RSM include the particular situations where several input variables potentially influence the performance or characteristic of any process [16,17]. This study investigates how the operating conditions such as salt concentration, salt solution temperature and processing time influence the dehydration (i.e. partial dewatering) of pumpkin samples and thus optimizing the osmotic dehydration process to provide maximum water loss and minimum solute gain by using response surface methodology.

\section{Materials and Methods}

\section{Preliminary experiments}

Screening experiments were conducted prior to the actual experiments to investigate the influences of five different operating conditions on osmotic dehydration of pumpkin. Temperature, time, solution to sample ratio, size of sample and solution concentrations were the initially investigated variables. Afterward, the variables which had remarkable effects on the osmotic dehydration of pumpkin were

*Corresponding author: M Enamul Hoque, Department of Mechanical Materials and Manufacturing Engineering, University of Nottingham Malaysia Campus, 43500 Selangor Darul Ehsan, Malaysia, Tel: 601-626-906-21; E-mail: enamul.hoque@nottingham.edu.my; enamul1973@gmail.com

Received February 17, 2015; Accepted May 15, 2015; Published May 20, 2015

Citation: Rahman SMA, Hoque ME, Rahman S, Hasanuzzaman M (2015) Osmotic Dehydration of Pumpkin Using Response Surface Methodology - Influences of Operating Conditions on Water Loss and Solute Gain. J Bioprocess Biotech 5: 226 doi:10.4172/2155-9821.1000226

Copyright: $\odot 2015$ Atiqur Rahman SM et al. This is an open-access article distributed under the terms of the Creative Commons Attribution License, which permits unrestricted use, distribution, and reproduction in any medium, provided the original author and source are credited. 
Citation: Rahman SMA, Hoque ME, Rahman S, Hasanuzzaman M (2015) Osmotic Dehydration of Pumpkin Using Response Surface Methodology Influences of Operating Conditions on Water Loss and Solute Gain. J Bioprocess Biotech 5: 226 doi:10.4172/2155-9821.1000226

Page 2 of 6

continued to be investigated for subsequent studies. These parameters were determined based on preliminary results.

\section{Experimental design}

The experimental design was prepared adopting the three factors three levels Box-Behnken design concept. The three influential independent variables were identified to be the salt concentration, processing time and solution temperature, while the dependent variables were the water loss and solute gain. The actual values and the corresponding coded values $(-1,0,1)$ of the independent variables are given in Table 1. The Box-Behnken design [18] can be illustrated by a cube with $\mathrm{x}, \mathrm{y}$ and $\mathrm{z}$ axes, where each axis represents one independent variable as shown in Figure 1. Each axis is divided equally into three points to denote the coded values $(-1,0,1)$. The design requires 17 runs of experiments having combination of specified variables corresponding to the spheres on the cube; 12 runs are located at the midpoint of the edges of the cubes (white sphere) and 5 replicate runs at the center point (black sphere). The whole set of 17 experimental runs is presented in Table 2 .

Two approximating second-order polynomial model relating the water loss and solute gain to the variables was developed by fitting the experimental data:

$$
Y=\beta_{o}+\sum_{i=1}^{n} \beta_{i} X_{i}+\sum_{i=1}^{n} \beta_{i i} X_{i}^{2}+\sum_{i=1}^{n-1} \sum_{j=i+1}^{n} \beta_{i j} X_{i} X_{j}
$$

Experiment design, analysis of variance, fitting of the quadratic polynomial model, drawing of response surface plots and optimization were performed using statistical software, Design-Expert 6.0.

\section{Experimental procedure}

Mature pumpkins (Cucurbita moschata) selected on the basis of similar size and colors were obtained from a local supermarket. The inner part (seeds) and outer layer (skin) of the pumpkin were removed using a spoon and a knife. The remaining portion of the pumpkins was then washed and sliced into samples with specified dimensions of $2 \mathrm{~cm}$ $\times 2 \mathrm{~cm} \times 5 \mathrm{~cm}$, and stored in the refrigerator for further experiments. The experiments were conducted using approximately $25 \mathrm{~g}$ of sliced pumpkin samples under the specified pre-designed operating conditions as presented in Table 2. Osmotic solution was prepared by dissolving the required amount of sodium chloride $(\mathrm{w} / \mathrm{v})$ in distilled

Table 1: Design of independent variables.

\begin{tabular}{|c|c|c|c|c|c|}
\hline & & & \multicolumn{3}{|c|}{ Coded values } \\
\hline Variables & Symbol & Unit & -1 & 0 & 1 \\
\hline Temperature & $\mathrm{X}_{1}$ & ${ }^{\circ} \mathrm{C}$ & 30 & 50 & 70 \\
\hline Concentration & $\mathrm{X}_{2}$ & $\%(\mathrm{w} / \mathrm{v})$ & 5 & 15 & 25 \\
\hline Time & $\mathrm{X}_{3}$ & minute & 30 & 90 & 150 \\
\hline
\end{tabular}

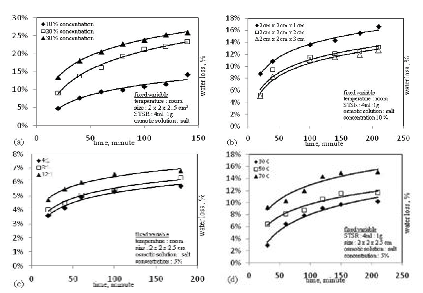

Figure 1: A three factors three levels box-behnken design. water. Constant solution to pumpkin sample ratio :1 (v/w) was used for all experiments. Osmotic solution temperature was controlled by water bath. Temperature variation was not more than $\pm 1^{\circ} \mathrm{C}$. After osmotic dehydration treatment, the pumpkin samples were taken out of the osmotic solution and rinsed with water to remove any surplus solvent adhering to the surfaces. The free water present onto the surface of the samples was then removed using absorbent paper, and weighted before placing into the hot air oven for further dehydration for 24 hours to obtain their bone dry mass.

\section{Measurements and calculations}

Water loss (WL) and solute gain (SG) were expressed as \% (w/w) of initial weight according to the following equations:

$$
\begin{aligned}
& W L=\frac{\left(W_{o}-W_{t}\right)+\left(S_{t}-S_{o}\right)}{W_{0}} \times 100 \\
& S G=\frac{\left(S_{t}-S_{o}\right)}{W_{0}} \times 100
\end{aligned}
$$

\section{Results and Discussions}

\section{Preliminary experiments}

Figure 2 shows the variation of water loss over time with (a) solution concentration, (b) sample size (thickness), (c) solution to sample ratio and (d) solution temperature. The solution concentration had the highest effect on the water loss followed by solution temperature. The similar findings were also observed in another research [15]. Both the solution to sample ratio and sample thickness had relatively lower influences on the water loss in compared to other two variables (i.e. solution concentration and solution temperature). A similar trend was also observed in case of solute gain over time. Therefore, the solute concentration, processing time and solution temperature were chosen to be the major process parameters for subsequent investigations.

\section{Statistical analysis and verification of experiments}

Two models were tested for their adequacy using ANOVA software. F-values for lack of fit $(\mathrm{p}<0.05)$ were found to be insignificant confirming the validity of models. A good fit was obtained for solute

Table 2: Experimental design and results of experiment

\begin{tabular}{|c|c|c|c|c|c|}
\hline & \multicolumn{3}{|c|}{ Coded process variables } & \multicolumn{2}{c|}{ Responses } \\
\hline Run & $\mathbf{X}_{1}$ & $\mathbf{X}_{2}$ & $\mathbf{X}_{3}$ & SG & WL \\
\hline 1 & -1 & -1 & 0 & 1.19 & 5.31 \\
\hline 2 & -1 & 0 & -1 & 0.28 & 5.44 \\
\hline 3 & -1 & 0 & 1 & 3.72 & 12.64 \\
\hline 4 & -1 & 1 & 0 & 3.45 & 10.50 \\
\hline 5 & 0 & -1 & -1 & 1.05 & 4.38 \\
\hline 6 & 0 & -1 & 1 & 1.24 & 8.38 \\
\hline 7 & 0 & 0 & 0 & 2.85 & 8.48 \\
\hline 8 & 0 & 0 & 0 & 2.51 & 8.23 \\
\hline 9 & 0 & 0 & 0 & 2.49 & 8.80 \\
\hline 10 & 0 & 0 & 0 & 2.45 & 8.63 \\
\hline 11 & 0 & 0 & 0 & 3.21 & 9.10 \\
\hline 12 & 0 & 1 & -1 & 0.14 & 5.49 \\
\hline 13 & 0 & 1 & 1 & 6.23 & 16.25 \\
\hline 14 & 1 & -1 & 0 & 3.13 & 8.10 \\
\hline 15 & 1 & 0 & -1 & 1.23 & 6.40 \\
\hline 16 & 1 & 0 & 1 & 6.19 & 16.77 \\
\hline 17 & 1 & 1 & 0 & 4.7 & 14.46 \\
\hline
\end{tabular}


Citation: Rahman SMA, Hoque ME, Rahman S, Hasanuzzaman M (2015) Osmotic Dehydration of Pumpkin Using Response Surface Methodology Influences of Operating Conditions on Water Loss and Solute Gain. J Bioprocess Biotech 5: 226 doi:10.4172/2155-9821.1000226

Page 3 of 6

gain $\left(\mathrm{R}^{2}=0.97\right)$ and water loss $\left(\mathrm{R}^{2}=0.95\right)$.

\section{Influence of variables on solute gain}

The p-values as presented in Table 3 indicate that all linear terms of the process variables, the quadratic term of temperature and the interaction term of "concentration and temperature" have significant effects on solute gain at a minimum of $95 \%$ confidence level. These findings are in agreement with other study [7]. Solution concentration was found to be the most influential process parameter $(\beta=1.84)$ followed by processing time $(\beta=0.99)$ and solution temperature $(\beta=0.83)$. The quadratic model developed in coded form (at 95\% confidence level) excluding the non-significant terms is presented as follows:

Solute gain $=2.7+0.83 \mathrm{X}_{1}+1.84 \mathrm{X}_{2}+0.99 \mathrm{X}_{3}+0.55 \mathrm{X}_{1}^{2}+1.48 \mathrm{X}_{2} \mathrm{X}_{3}$

Response surface graphs were plotted showing the influences of concentration and temperature on solute gain as demonstrated in Figure 3, where the time was kept constant for (a) 30 minutes, (b) 90 minutes and (c) 150 minutes. As observed in Figure 3a, the concentration had relatively lower influence on solute gain at shorter processing time (e.g. 30 minutes) and lower temperature (e.g. $\left.30^{\circ} \mathrm{C}\right)$. However, at higher temperature the solute gain increased with the increase of solution concentration. It was also observed that the solution temperature had a positive influence on solute gain regardless of solution concentration at lower processing time. Figures $3 b$ and $3 c$ evidenced that at longer processing time the effects of temperature on solute gain became more pronounced even at lower temperature. Moreover, at longer processing times the effect of temperature on solute gain was found to be less significant.

\section{Influence of process variables on water loss}

The p-values as reported in Table 3, indicate that all linear terms of the process variables, the quadratic term of temperature and interaction

terms of "temperature and concentration" and "concentration and time" have significant effects on water loss at a minimum of $95 \%$ confidence level. The relative magnitude of $\beta$ indicates maximum positive contribution towards water loss by solution concentration $(\beta=4.04)$ followed by processing time $(\beta=2.56)$ and solution temperature

Table 3: The coefficients of the model with their respective $\beta$ value, $p$-value and $r^{2}$ value.

\begin{tabular}{|c|c|c|c|c|}
\hline & \multicolumn{2}{|c|}{ Water loss, $Y_{1}$} & \multicolumn{2}{|c|}{ Solute gain, $Y_{2}$} \\
\hline & $\beta$ & p-value & $\beta$ & p-value \\
\hline Constant & 8.64 & & 2.7 & \\
\hline \multicolumn{5}{|l|}{ Linear } \\
\hline Temperature & 1.48 & 0.0002 & 0.83 & $0.0005^{*}$ \\
\hline Concentration & 4.04 & $<0.0001^{*}$ & 1.84 & $<0.0001^{\star}$ \\
\hline Time & 2.56 & $<0.0001^{*}$ & 0.99 & $0.0001^{\star}$ \\
\hline \multicolumn{5}{|l|}{ Quadratic } \\
\hline Temp $\times$ temp & 1.32 & $0.0029^{*}$ & 0.55 & $0.0204^{*}$ \\
\hline Conc $\times$ Conc & 0.35 & 0.2750 & -0.40 & 0.0668 \\
\hline Time $\times$ time & -0.37 & 0.2544 & -0.14 & 0.4872 \\
\hline \multicolumn{5}{|l|}{ Interaction } \\
\hline Temp $\times$ Conc & 0.79 & $0.0350^{*}$ & 0.38 & 0.0853 \\
\hline Temp $\times$ Time & 0.29 & 0.3661 & -0.17 & 0.3892 \\
\hline Conc $\times$ Time & 1.69 & $0.0009^{*}$ & 1.48 & $0.0001^{*}$ \\
\hline Lack of fit & & 0.0518 & & 0.2866 \\
\hline $\mathrm{R}^{2}$ & 0.97 & & 0.95 & \\
\hline
\end{tabular}
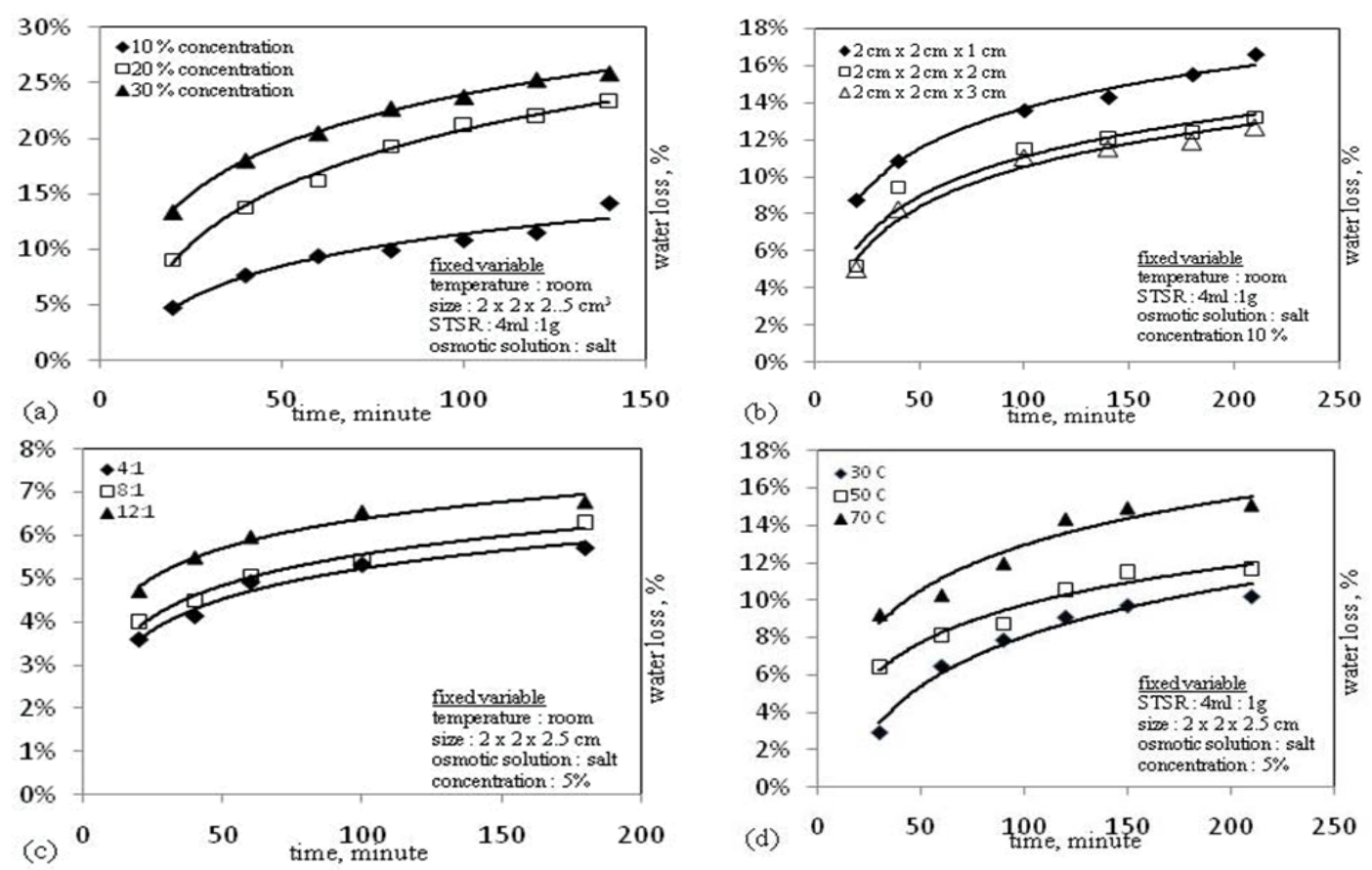

Figure 2: Influence of various operating conditions on water loss of pumpkin: (a) solution concentration (b) size (thickness) of sample (c) solution to sample ratio ( $\mathrm{v} / \mathrm{w}$ ) (d) solution temperature. 
Citation: Rahman SMA, Hoque ME, Rahman S, Hasanuzzaman M (2015) Osmotic Dehydration of Pumpkin Using Response Surface Methodology Influences of Operating Conditions on Water Loss and Solute Gain. J Bioprocess Biotech 5: 226 doi:10.4172/2155-9821.1000226
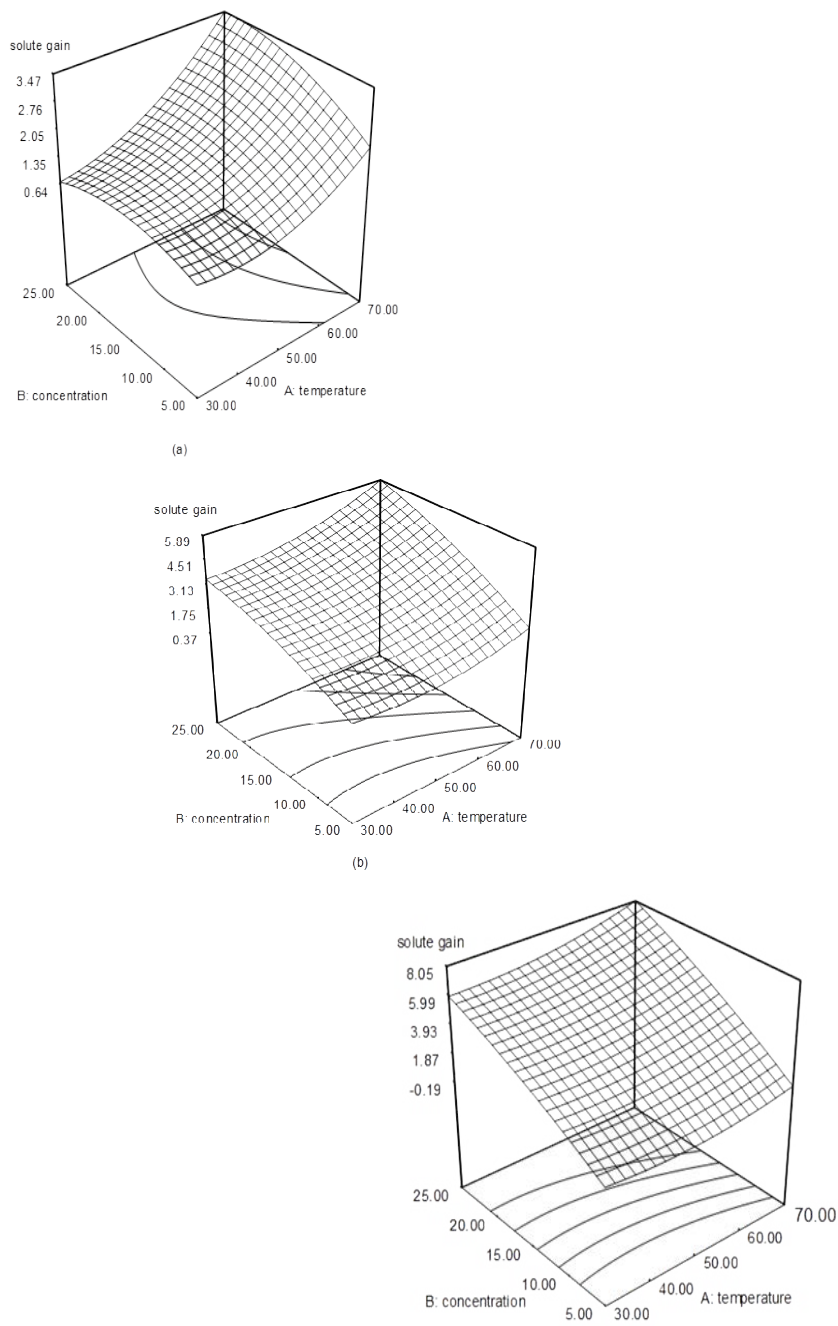

(c)

Figure 3: Influence of concentration and temperature on solute gain of pumpkin samples at different process time, (a) 30 minutes, (b) 90 minutes and (c) 150 minutes.

$(\beta=1.48)$. The quadratic model developed in coded form (at $95 \%$ confidence level) excluding the non-significant terms is presented as follows:

Water loss $=8.64+1.48 \mathrm{X}_{1}+4.04 \mathrm{X}_{2}+2.56 \mathrm{X}_{3}+1.32 \mathrm{X}_{1}^{2+} 0.79 \mathrm{X}_{1} \mathrm{X}_{2}+1.69 \mathrm{X}$ ${ }_{2} \mathrm{X}_{3}$-------- [5]

The influences of varying temperature and time are shown in Figure 4, where the solution concentration was kept constant at (a) 5\%, (b) $15 \%$ and (c) $25 \%$. As demonstrated in Figure 4a, the water loss increased slowly with the increase of temperature up to 40 afterward the rate of water loss increased rapidly.

It also indicates that the water loss increased as the processing time increased. However, the effect of processing time on water loss was not found to be as pronounced as the effect of temperature at lower solution concentration (e.g. 5\%). As the solution concentration increased as shown in Figures $4 \mathrm{~b}$ and $4 \mathrm{c}$, the rate of increase of water loss due to both temperature and processing time became more gradual. At all three different concentrations, highest water loss was achieved at maximum solution temperature and processing time.

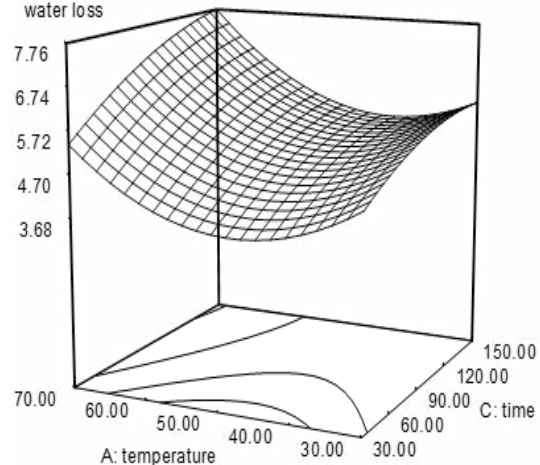

(a)

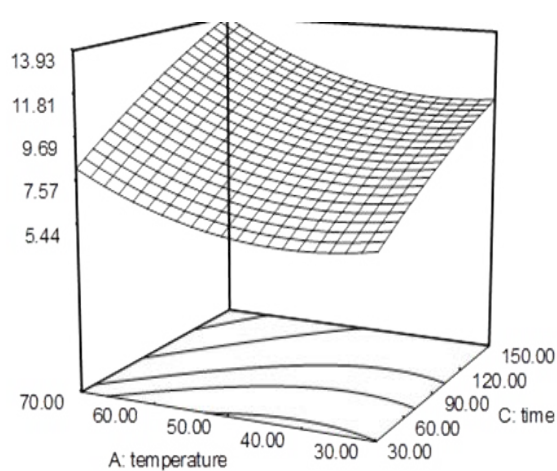

(b)

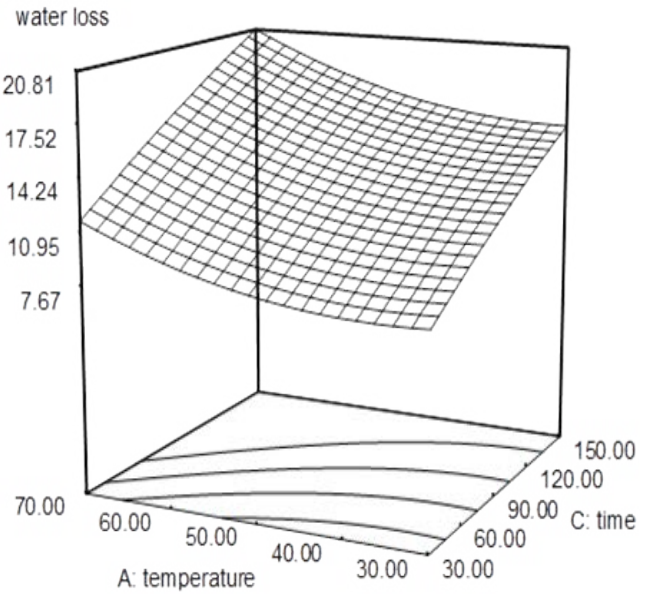

(c)

Figure 4: Influence of process time and temperature on water loss of pumpkin samples at different solution concentration, (a) $5 \%$, (b) $15 \%$ and (c) $25 \%$.

Table 4: Criteria of variables and responses for optimization of osmotic dehydration of pumpkin.

\begin{tabular}{|c|c|c|c|}
\hline Process & Target & Range & Importance \\
\hline Variables & & & \\
\hline Temperature & Is in range & $30-70$ & 3 \\
\hline Concentration & Is in range & $5-25$ & 3 \\
\hline Time & Is in range & $30-150$ & 3 \\
\hline Responses & & & \\
\hline Solution gain & Minimize & $0.14-6.23$ & 2 \\
\hline Water loss & Minimize & $4.38-16.8$ & 5 \\
\hline
\end{tabular}


Citation: Rahman SMA, Hoque ME, Rahman S, Hasanuzzaman M (2015) Osmotic Dehydration of Pumpkin Using Response Surface Methodology Influences of Operating Conditions on Water Loss and Solute Gain. J Bioprocess Biotech 5: 226 doi:10.4172/2155-9821.1000226

Page 5 of 6

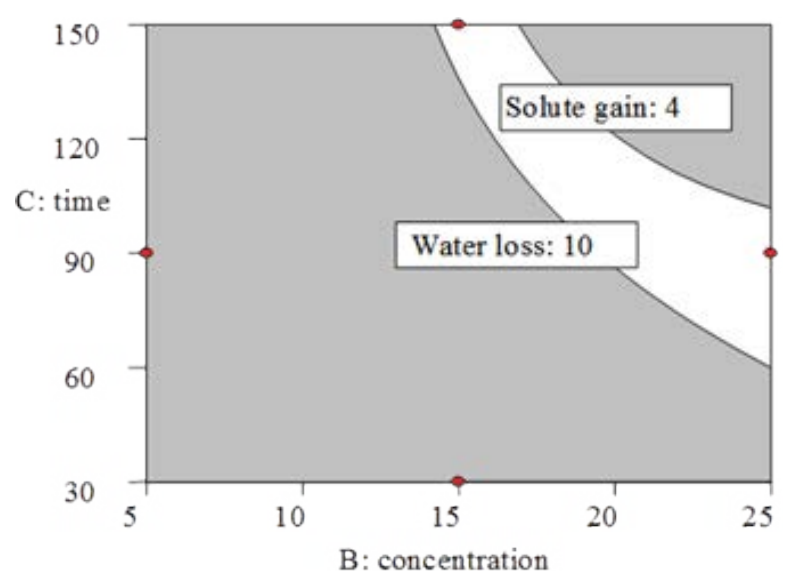

(a)

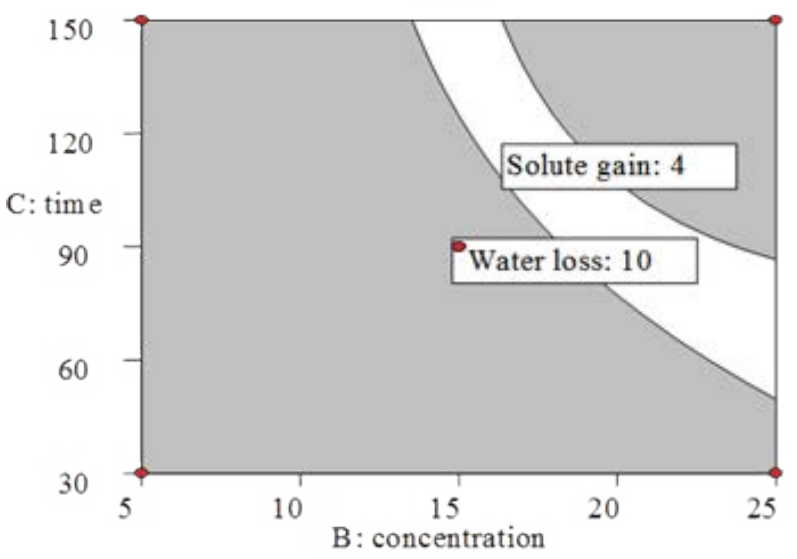

(b)

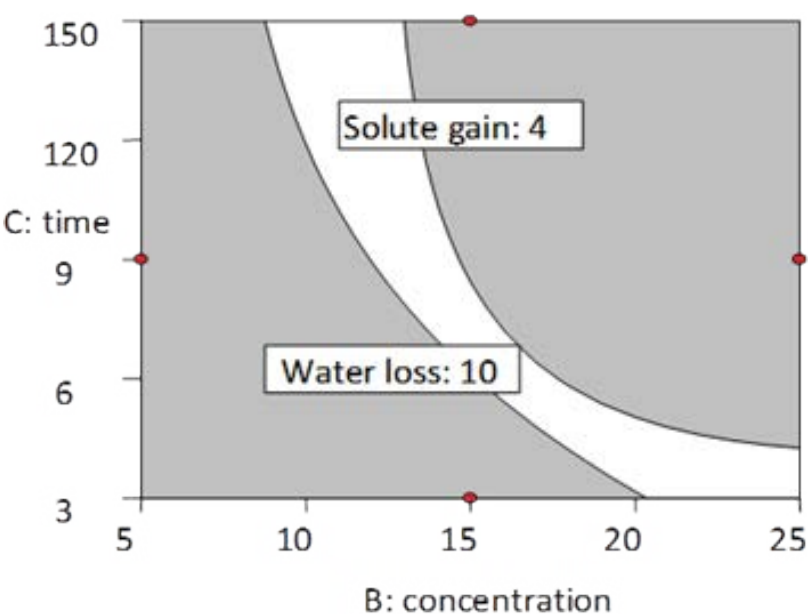

(c)

Figure 5: Overlaid contours for time and concentration at different temperatures (a) $30^{\circ} \mathrm{C}$ (b) $50^{\circ} \mathrm{C}$ and $(\mathrm{c}) 70^{\circ} \mathrm{C}$.

\section{Optimization}

A graphical multi-response optimization technique was adopted to determine the workable optimum conditions for the osmotic dehydration of pumpkin. The contour plots for both water loss and solute gain were superimposed into an overlay plot and the regions that best satisfied all the constraints were selected. The criteria for the constraint were set so that any experiment conducted under the operating conditions within the optimum regions should result in a favorable water loss to solute gain ratio. The constraint for water loss was set at a minimum of $10 \%$ and solute gain at a maximum of $4 \%$ resulting in a minimum of 2.5 water loss to solute gain ratio. These constraints resulted in a feasible zone identified as the un-shaded area in the superimposed contour plots as shown in Figure 4. Any points that falls within the optimum region should have water loss $>10 \%$ and solute gain $<4 \%$.

At $30^{\circ} \mathrm{C}$, it was observed that the process time and solution concentrations were to some extent competing, where a high process time with a slightly lower solution concentration yielded optimum results and vice-versa. As the temperature increased the degree where these two variables were competing increased gradually. As shown in Figures $4 \mathrm{~b}$ and $4 \mathrm{c}$, the optimum regions slowly shifted towards the left, where high process time with a slightly lower solution concentration no longer fell in the optimum region. At $70^{\circ} \mathrm{C}$, the optimum region fell in the area of either high process time combined with intermediate solution concentration, or high solution concentration combined with low process time. A more precise optimization of the osmotic dehydration of pumpkin was achieved by pin-pointing the exact process variables that yielded maximum water loss and minimum solute gain. Targets for the process variables and the responses along with their priorities (shown as importance) that have to be pre-determined are summarised in Table 4

The optimum operating conditions were found to be the solution temperature, salt concentration and processing time of $65.76^{\circ} \mathrm{C}, 25 \%$ and 63.29 minutes, respectively. Correspondingly the achieved solute gain and water loss at optimum conditions were $4.36 \%$ and $13.57 \%$, respectively (Figure 5).

\section{Conclusions}

Osmotic dehydration of pumpkin was successfully studied using response surface methodology. All three dominating process variables (i.e. solution concentration, solution temperature and processing time) had direct effects on both water loss and solute gain. A feasible region that yielded a minimum water loss to solute gain ratio of 2.5 was generated using statistical software. The optimized values for the dominating process variables i.e. solution temperature, salt concentration and processing time were found to be of $65.76^{\circ} \mathrm{C}, 25 \%$ and 63.29 minutes, respectively. The optimum conditions accordingly yielded minimum solute gain and maximum water loss of $4.36 \%$ and $13.57 \%$, respectively. In conclusion, the Response Surface Methodology (RSM) was shown to be promising in optimizing the process parameters for osmotic dehydration of pumpkin in salt solution, which could serve as strong guideline for industrial dehydration of crops like pumpkin.

\section{References}

1. Kanagaratnam S, Hoque ME, Sahri MM, Spowage A (2013) Investigating the effect of deforming temperature on the oil-binding capacity of palm oil based shortening. J Food Eng 118: 90-99.

2. Rahman S (1999) Handbook of Food Preservation. CRC Press, Boca Raton, FL 33487, USA.

3. Silva KS, Fernandes MA, Mauro MA (2014) Effect of calcium on the osmotic dehydration kinetics and quality of pineapple. J Food Eng 134: 37-44.

4. Silva KS, Caetano LC, Garcia CC, Romero JT, Santos AB, et al. (2011) Osmotic dehydration process for low temperature blanched pumpkin. J Food Eng 105: 56-64

5. Mayor L, Cunha RL, Sereno AM (2007) Relation between mechanical properties and structural changes during osmotic dehydration of pumpkin. Food Res Int 40: $448-460$. 
Citation: Rahman SMA, Hoque ME, Rahman S, Hasanuzzaman M (2015) Osmotic Dehydration of Pumpkin Using Response Surface Methodology Influences of Operating Conditions on Water Loss and Solute Gain. J Bioprocess Biotech 5: 226 doi:10.4172/2155-9821.1000226

6. Mayor L, Moreira R, Sereno AM (2011) Shrinkage, density, porosity and shape changes during dehydration of pumpkin (Cucurbita pepo L.) fruits. J Food Eng 103: 29-37.

7. Silva MADC, Silva ZED, Mariani VC, Darche S (2012) Mass transfer during the osmotic dehydration of West Indian cherry. LWT - Food Sci Technol 45: 246-252.

8. Pan YK, Zhao LJ, Zhang Y, Chen G, Mujumdar AS (2003) Osmotic dehydration pretreatment in drying of fruits and vegetables. Dry Technol 21: 1101-1114.

9. Torreggiani D (1993) Osmotic dehydration in fruit and vegetable processing Food Res Int 26: 59-68.

10. Maran JP, Sivakumar V, Thirugnanasambandham K, Sridhar R (2013) Artificial neural network and response surface methodology modeling in mass transfer parameters predictions during osmotic dehydration of Carica papaya L. Alexandria Eng J 52: 507-516.

11. Alam MS, Singh A (2010) Optimization of osmotic dehydration process of Aonla fruit in salt solution. Int J Food Eng 6: 1556-3758

12. Panades G, Fito P, Aguiar Y, deVillavicencio MN, Acosta V (2006) Osmotic dehydration of guava: Influence of operating parameters on process kinetics. J Food Eng 77: 383-389.
13. Cataldo A, Cannazza G, deBenedetto E, Severini C, Derossi A (2011) An alternative method for the industrial monitoring of osmotic solution during dehydration of fruit and vegetables: A test-case for tomatoes. J Food Eng 105 186-192.

14. Abraão AS, Lemos AM, Vilela A, Sousa JM, Nunes FM (2013) Influence of osmotic dehydration process parameters on the quality of candied pumpkins. Food Bioprod Process 91: 481-494.

15. Ispir A, Togrul IT (2009) Osmotic dehydration of apricot: Kinetics and the effect of process parameters. Chem Eng Res Des 87: 166-180.

16. Singh B, Panesar PS, Nanda V, Gupta AK, Kennedy JF (2006) Application of response surface methodology for the osmotic dehydration of carrots. J Food Process Eng 29: 592-614.

17. Eren I, Kaymak-Ertekin F (2007) Optimization of osmotic dehydration of potato using response surface methodology. J Food Eng 79: 344-352.

18. Annadurai G, Sheeja RY (1998) Use of Box-Behnken design of experiments for the absorption of verofix red using biopolymer. Bioprocess Eng 18: 463-466. 